\title{
Electrochemically controlled ion exchange: proton ion exchange with sodium zeolite $X$ and $A$
}

\author{
Michael J. Stephenson ${ }^{1,3} \cdot$ Martin P. Attfield $^{1} \cdot$ Stuart M. Holmes $^{2} \cdot$ Robert A. W. Dryfe $^{1}$
}

Received: 6 January 2015 / Revised: 2 April 2015 / Accepted: 3 April 2015 / Published online: 19 April 2015

(C) The Author(s) 2015. This article is published with open access at Springerlink.com

\begin{abstract}
Structural characterisation of proton-exchanged zeolites, prepared using ion-transfer at the liquid-liquid interface, is reported. Specifically, electrochemical exchange of protons for sodium with zeolites $\mathrm{X}$ and $\mathrm{A}$ is described: the structural integrity of the resultant materials was probed by solid-state NMR spectroscopy and temperature-dependent powder X-ray diffraction. It is shown that replacement of ca. $40 \%$ of the $\mathrm{Na}^{+}$can be achieved using this approach for both zeolites; however, the results indicate that exchange is accompanied by significant structural degradation in the case of zeolite A, with proton exchange occurring at the amorphous regions of the sample. In contrast, zeolite $\mathrm{X}$ retains its structure, and the level of proton exchange is comparable with the highest levels reported using conventional chemical methods, highlighting the utility of the electrochemical approach.
\end{abstract}

Keywords Ion exchange $\cdot$ Proton $\cdot$ Zeolite

\section{Introduction}

Zeolites have numerous applications in separation, filtration and catalysis. Their importance as heterogeneous catalysts stems from their use as either active catalysts [1] or as

Robert A. W. Dryfe

robert.dryfe@manchester.ac.uk

1 School of Chemistry, University of Manchester, Oxford Road, Manchester M13 9PL, UK

2 School of Chemical Engineering and Analytical Science, University of Manchester, Oxford Road, Manchester M13 9PL, UK

3 Present address: Metalysis Ltd, Unit 2, Farfield Park, Manvers Way, Wath upon Dearne, Rotherham S63 5DB, UK supporting substrates [2]. Their uniform porous nature presents a high-internal surface area and gives good access to active sites. They are successfully employed for acidmediated reactions, such as catalytic cracking [3], and combine high thermal and chemical stability with excellent activity. Zeolite catalysis can also introduce size and shape selectivity [4].

Protonated zeolites are the principle component of cracking catalysts [5] and can be prepared by the treatment of the zeolite with strong acids. However, many crystalline zeolites decompose when treated with strong acids, so this method is only effective for high-silica zeolites [6]. Protonated forms can be prepared by other methods. A common method involves cation exchange from an ammonium solution, followed by thermal treatment to liberate ammonia, thus forming the protonated zeolite. This method is not successful for all zeolites, attempts to achieve complete exchange for zeolite $\mathrm{X}$ and $A$ results in structural disintegration $[6,7]$. It is possible to achieve partial proton exchange via the ammonium route with $\mathrm{NaA}$ (proton equivalent fraction, $E_{\mathrm{H}}$ $<0.35)$ [7, 8] and $\mathrm{NaX}\left(E_{\mathrm{H}}<0.33\right)$ [9] in each case calcinations of the partially ammonium exchanged zeolite needs to be carried out at slow heating rates in a dry atmosphere. The partially exchanged $\mathrm{NaX}$ sample also retains good crystallinity $(>90 \%)$.

Sodium cations present in large zeolite cavities undergo some ion exchange when the zeolite is suspended in water. Sodium ions are replaced by hydrated hydrogen ions [6]; the extent of exchange is dependent on the $\mathrm{pH}$ of the solution. When $\mathrm{NaX}$ was titrated with $\mathrm{HCl}$, breaks were observed in the curve at $\left(E_{\mathrm{H}}=\right) 0.34$ (at pH 6.35) and $\left(E_{\mathrm{H}}=\right) 0.58$ (at pH 4.8) proton equivalent fraction [10]. The samples are described as 'highly crystalline' at these points, though no crystallinity data is given. 
A study of $\mathrm{NaA}$ at a range of $\mathrm{pH}$ values was conducted by Cook et al. [11]; they observed that at $\mathrm{pH}$ of 5 (or less), the dissolution of aluminium occurred followed by a precipitation reaction. At neutral $\mathrm{pH}$, the $\mathrm{NaY}$ zeolite could be protonexchanged using a flow-through system to $40 \%$, but the resultant zeolite was completely amorphous. At $25 \%$ exchange, the zeolite had lost $50 \%$ of its crystallinity.

Alternatively, proton exchange can be performed under anhydrous conditions. Silver-exchanged $\mathrm{NaA}$ can be reduced over hydrogen to metallic silver and proton-exchanged $\mathrm{NaA}$; over $40 \%$ proton exchange has been achieved by this method [12]. Another method was to mix NaA powder with an anhydrous $p$-toluenesulphonic acid in dioxane solution [13]. The solubility of $p$-toluenesulphonic in dioxane is high whereas that of the sodium salt of $p$-toluenesulphonic in dioxane is low; hence as exchange occurs, sodium $p$-toluenesulphonic precipitates and drives proton exchange. Seventy percent proton exchange has been achieved employing this method with the product retaining good crystallinity. It is interesting to note that protonated zeolites made by all of these methods have low stability on exposure to water vapour.

In a previous paper, we described an alternative method for controlled ion exchange of zeolites, based on electrochemistry at the liquid-liquid interface [14]. It was demonstrated that protons can be exchanged into NaY using a weak acid. This method avoids the use of strong acids which can damage the zeolite structure. It also avoids the need for high-temperature regimes required for protonation via ammonium exchange and calcinations. The electrochemical method also negates the need to refresh the donor ion solution repeatedly to achieve required levels of exchange, and so reduces waste and costs. These milder conditions make this technique ideal for ion exchange of zeolite-modified electrodes and zeolite membranes, both of which are employed in separation studies including electroanalytical techniques, for example, and typically have poor mechanical and thermal stability [15].

In this manuscript, the extension of the electrochemicalexchange approach to the protonation of $\mathrm{NaX}$ and $\mathrm{NaA}$ is described, along with investigations of the integrity of the resultant structures. It is shown that the $E_{\mathrm{H}}$ values obtained through the electrochemical approach, for zeolite $\mathrm{X}$ in particular, can exceed 0.5 , which is higher than the values reported using conventional chemical methods.

\section{Experimental}

The aqueous solutions were made using water obtained from 'ELGA purelab ultra' purification system (Vivendi Water Systems Ltd., High Wycombe, UK), boric acid ( $99.995 \%$, Aldrich), sulphuric acid (ARISTAR grade, BDH), sodium zeolite A (NaA, 0.5-5.0 $\mu \mathrm{m}, \mathrm{BDH})$, and sodium zeolite $\mathrm{X}(\mathrm{NaX}, \mathrm{BDH})$. The $\mathrm{Na}^{+}$ content of the as-purchased zeolites was $>99 \%$ as measured by inductively coupled plasma atomic emission spectroscopy (ICPAES) performed on the fresh samples. The organic solution was made using 1,2-dichloroethane (DCE, $99.8 \%+$, Aldrich, Dorset, UK) as the solvent, dibenzo-18-crown-6 (DB18c6, $98 \%$, Lancaster Chemicals Co., Morecambe, UK) was employed as the complexing agent and bis(triphenylphosphoranylidene)ammonium tetrakis(pentafluorophenyl) borate $\left(\mathrm{BTPPATPBF}_{20}\right)$ was used as the background electrolyte. The organic phase electrolyte was prepared by metathesis of bis(triphenylphosphoranylidene) ammonium chloride $(99 \%+$, Aldrich) and lithium tetrakis(pentafluorophenyl) borate (Boulder Scientific, Mead, $\mathrm{CO}$, USA), according to a previously reported procedure [16].

The electrochemical cell was comprised of two half-cells [14]; the upper half-cell contained the zeolite suspension in the aqueous exchange medium. For all ion-exchange experiments, a $2.5 \mathrm{wt} \%$ zeolite suspension was employed. The lower half-cell contained the organic phase, which was stirred at $4 \mathrm{~Hz}$ using a magnetic bar and stirrer. The liquid/liquid interface was supported by a polyethylene terephthalate "tracketched' (PET) membrane $(0.1 \mu \mathrm{m}$ pore diameter "Poretics" film, Osmonics Inc., Livermore, CA, USA). This was used to aid separation of the two phases and allowed the easy removal of the zeolite sample. The membrane also stabilized the interface when the organic phase was stirred. A silver/silver borate reference electrode was used in the aqueous phase, and a silver/silver tetraphenylborate pseudo-reference electrode was used in the organic phase, the latter being prepared according to a method previously described [17]. Platinum gauze was used as the counter electrode in both phases. The water/DCE interface was polarised, with potentials defined with respect to the aqueous phase, using a four-electrode potentiostat (Autolab PGSTAT 100, Eco-chemie, Utrecht, Netherlands). All experiments were performed at room temperature $(293 \pm 3 \mathrm{~K})$. The electrochemical cell can be written as:

\section{Cell 1}

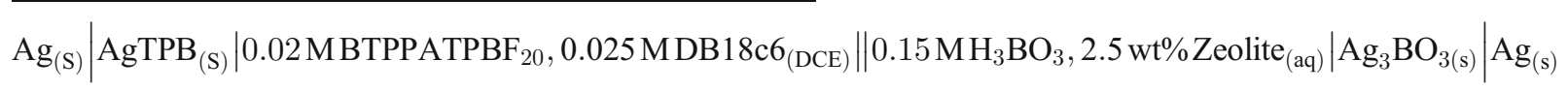

where the zeolite employed is either the $\mathrm{NaA}$ or $\mathrm{NaX}$ suspension. The double bar denotes the polarised interface.
The elemental composition of the zeolite samples following the electrochemical treatment was determined by ICPAES 
(Vista-MPX, Varian, Walton-on-Thames, UK). The samples were prepared for analysis by drying the zeolite overnight at $60^{\circ} \mathrm{C}$, dissolving in nitric acid $(69 \%$, AnalaR grade, $\mathrm{BDH}$, Poole, UK) and diluting with ultra pure water. The samples were then analysed for sodium and aluminium content, using three wavelengths per element.

The presence of exchanged protons in the zeolite samples was examined directly by solid-state magic-angle spinning nuclear magnetic resonance ( ${ }^{1} \mathrm{H}$-MASNMR). The aluminium content of the samples was examined indirectly by ${ }^{29} \mathrm{Si}$ MASNMR. Samples were prepared by heating under vacuum at a rate of $50 \mathrm{~K} \mathrm{~h}^{-1}$ to $573 \mathrm{~K}$. The samples were held under these conditions $(573 \mathrm{~K}, 0.1 \mathrm{mbar})$ for a further $24 \mathrm{~h}$ before sealing, under vacuum, in a glass ampoule $[18,19]$. MASN MR measurements were carried out at the EPSRC solid-state NMR facility of Durham University on a Varian UNITY Inova spectrometer, operating at a resonance frequency of 299.8 and $60 \mathrm{MHz}$, for ${ }^{1} \mathrm{H}$ - and ${ }^{29} \mathrm{Si}-\mathrm{MASNMR}$, respectively. The spectra were obtained with a sample spin rate of $3 \mathrm{kHz}$ and a recycle delay of $60 \mathrm{~s}$. Chemical shifts are quoted with respect to the signal for $\mathrm{Si}\left(\mathrm{CH}_{3}\right)_{4}(0.0 \mathrm{ppm})$.

The crystallinity of the zeolite samples was measured using powder X-ray diffraction experiments (XRD). These were carried out on a Philips 'X'Pert Pro' Pw3040/60 diffractometer using $\mathrm{Cu} \mathrm{K} \alpha$ radiation. All scans were continuous and run between $2 \theta$ values of $3-60^{\circ}$. The scan rate was $0.05^{\circ} \mathrm{s}^{-1}$. The samples were prepared by first drying (in air at $333 \mathrm{~K}$ ) and then grinding into a fine powder. The thermal stability of the samples was examined by XRD employing an in situ autoclave. The temperature was ramped from 298 to $1,173 \mathrm{~K}$ at $10 \mathrm{~K} \mathrm{~min}^{-1}$; at $50 \mathrm{~K}$ intervals, the temperature was held for $15 \mathrm{~min}$ and the XRD pattern recorded.

\section{Results and discussion}

Experiments were carried out using cell 1 . The water/DCE interface was held at a potential where $\mathrm{Na}^{+}$is transferred preferentially over $\mathrm{H}^{+}$[14]. The experiments were performed over various electrolysis times, and the charged passed was recorded. Assuming all the current is due to $\mathrm{Na}^{+}$transfer, the charge passed can be directly related to the amount of $\mathrm{Na}^{+}$transferred, and so the $\mathrm{Na}^{+}$content of the suspension can be followed and controlled. Boric acid was chosen as the proton source as it is mildly acidic (pH 5.3-5.9), and so should not damage the zeolite structure significantly.

The degree of protonation of the electrochemically enhanced proton exchange samples (from herein referred to as electrochemical samples) was measured by ICPAES. Figure 1 shows that the degree of protonation increases linearly with charge transfer for both $\mathrm{NaX}$ and $\mathrm{NaA}$. After the transfer of circa $25 \mathrm{C}$ (equivalents of $\mathrm{Na}^{+}$), circa $45 \%$ proton exchange was achieved for both zeolites. It should be noted that this
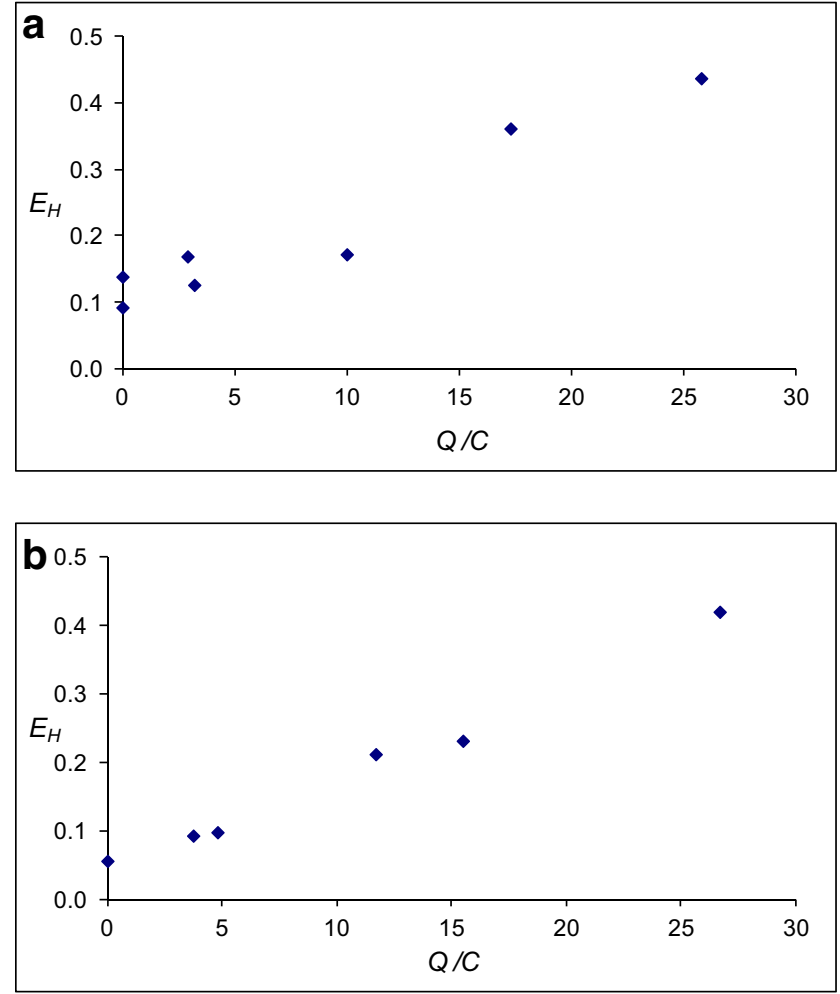

Fig. 1 Plot of $E_{\mathrm{H}}$ values versus total charged passed, $Q$. Cell 1 was used where the zeolite used was $\mathbf{a} \mathrm{NaX}$ and $\mathbf{b} \mathrm{NaA}$

does not take into account any damage that may have occurred to the respective zeolite samples and so does not distinguish between protonation of crystalline or amorphous regions.

Consequently, the structural integrity of the electrochemical samples was investigated by XRD. Figure 2 shows the XRD patterns of the fresh samples compared with different extents of electrochemically enhanced ion exchange and a chemically exchanged sample with a strong acid $(0.1 \mathrm{M}$ sulphuric acid). It can be clearly seen that the electrochemical samples have the same diffraction pattern as the fresh zeolite sample, and therefore, must have retained at least some of their crystalline structure; whereas, for the chemically exchanged sample, the diffraction pattern has essentially disappeared indicating that the crystalline structure has been completely destroyed. It can also be seen that the peak intensities of the $\mathrm{NaX}$ samples are retained to a greater extent than the NaA samples. This indicates that the $\mathrm{NaX}$ samples are more stable to the experimental conditions and have retained their structural integrity to a greater extent than the $\mathrm{NaA}$ samples.

X-ray crystallinity can be measured to a first approximation by comparing the relative peak intensities of the exchanged samples with those of a fresh sample. For the NaX samples, the most height of the most intense peak, corresponding to diffraction from the (111) plane was used; whereas, the height of the (200) peak was used for NaY. Figure 3 shows the crystallinity of the electrochemical $\mathrm{NaX}$ samples against charge 

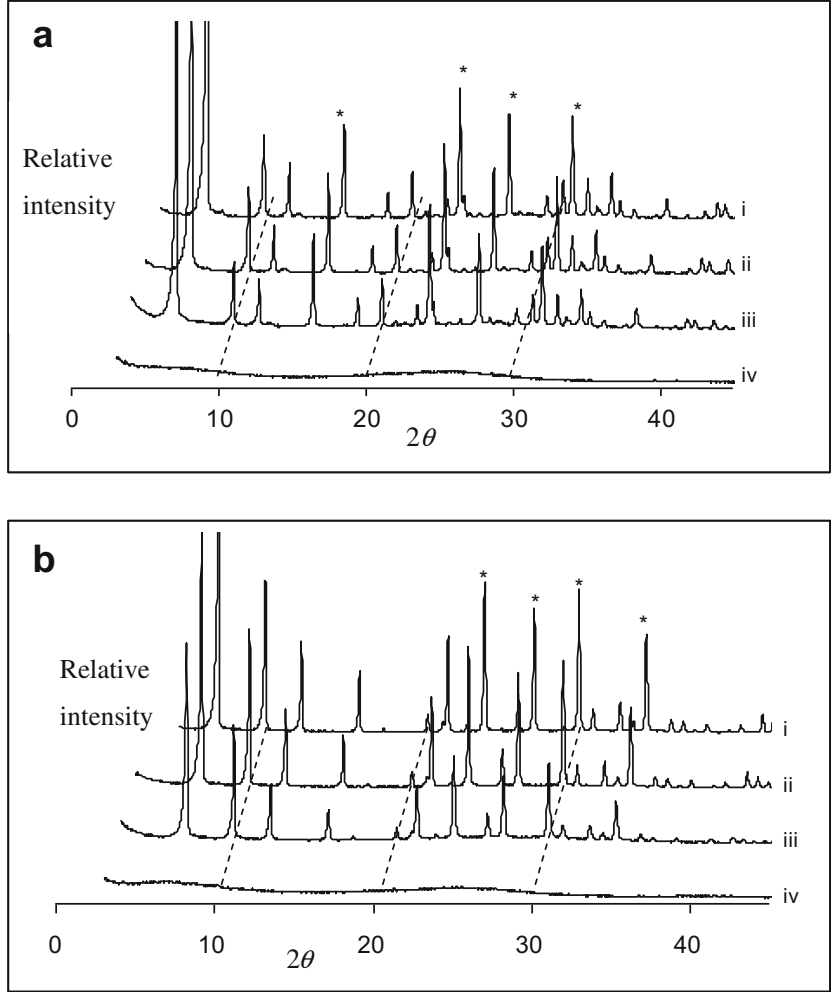

Fig. 2 X-ray powder diffraction patterns for $\mathbf{a} \mathrm{NaX}$ and $\mathbf{b} \mathrm{NaA}$ samples. a $i$-fresh $\mathrm{NaX}, i i$ - electrochemically exchanged $0.26-\mathrm{HNaX}$, iiielectrochemically exchanged $0.44-\mathrm{HNaX}$ and $i v-$ chemically exchanged with $0.1 \mathrm{M}$ sulphuric acid 0.97-HNaX. b $i$-fresh NaA, $i i-$ electrochemically exchanged $0.21-\mathrm{HNaA}$, iii-electrochemically exchanged $0.42-\mathrm{HNaA}$ and $i v$-chemically exchanged with $0.1 \mathrm{M}$ sulphuric acid $0.96-\mathrm{HNaA}$. The patterns have been shifted diagonally for clarity. The stars indicate the peaks used to measure crystallinity. The numerical prefix is the $E_{\mathrm{H}}$ value for the sample

transferred and extent of exchange. Forty-four percent exchange has been achieved with the loss of only $12 \%$ crystallinity: if it assumed that diffraction intensity is independent of the cation, this indicates that the bulk (ca. $32 \%$ ) of the exchange has occurred in crystalline regions. Figure 4 shows the crystallinity of electrochemical $\mathrm{NaA}$ samples against charge transferred and extent of exchange. It can be observed that the crystallinity of the sample drops with both charged passed and extent of exchange. The zeolite retains high crystallinity $\left(X_{\mathrm{cr}} \geq\right.$ $90 \%$ ) until about $20 \%$ extent of exchange. After which, there is a linear drop in crystallinity with increasing extent of exchange. Forty-two percent exchange has been achieved with the loss of $45 \%$ crystallinity; it is possible that the $45 \%$ loss in crystallinity could account for the entire proton exchange, i.e. proton exchange only occurs in amorphous regions or proton exchange destroys the crystallinity of the exchange site. For the samples with lower levels of exchange, the extent of exchange compared to the loss of crystallinity (10\% exchange with the loss of $2 \%$ crystallinity and $21 \%$ exchange with the loss of $10 \%$ crystallinity) indicates that at least $10 \%$ exchange has occurred in crystalline regions.
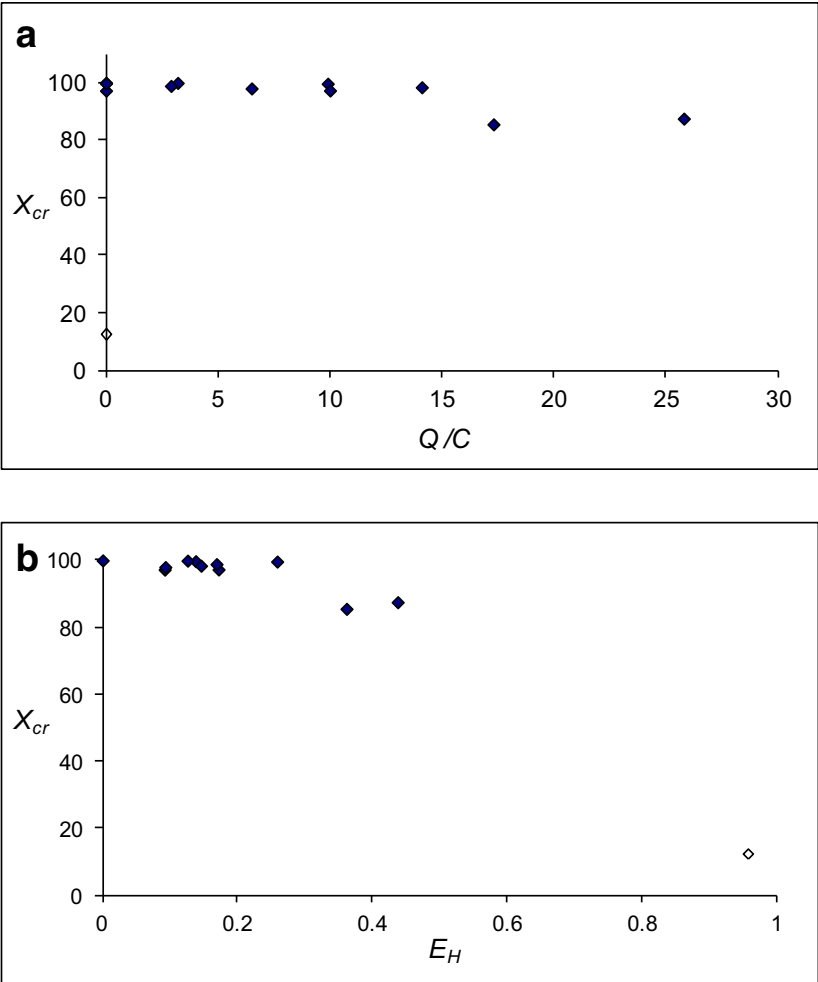

Fig. 3 Graph of percentage relative crystallinity, $X_{\text {cr }}$, versus a charged passed, $Q$, and $\mathbf{b} E_{\mathrm{H}}$. Cell 1 was employed where the zeolite was $\mathrm{NaX}$ (open diamond is purely chemical exchange with $0.1 \mathrm{M}$ sulphuric acid)
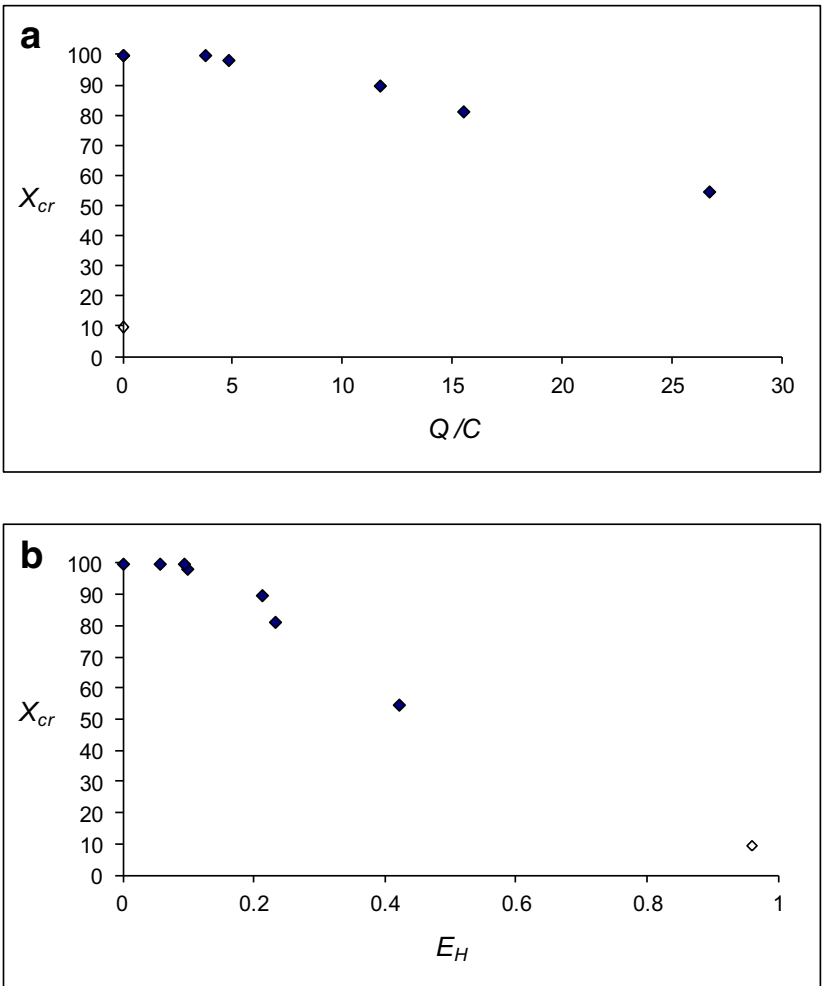

Fig. 4 Graph of percentage relative crystallinity, $X_{\mathrm{cr}}$, versus a charged passed, $Q$, and $\mathbf{b} E_{\mathrm{H}}$. Cell 1 was employed where the zeolite employed was $\mathrm{NaA}$ (open diamond is purely chemical exchange with $0.1 \mathrm{M}$ sulphuric acid) 
It should be noted that points at zero Coulombs relate to purely chemically exchanged samples and were the last samples to be measured; hence, they have been in contact with the acid solution for the longest period of time. In both cases (for $\mathrm{NaX}$ and $\mathrm{NaA}$ ), the samples have retained $100 \%$ crystallinity, which shows that both zeolites are resilient to the weak acid solution. It also means that any damage done to the electrochemical samples is due to either the electrochemical procedure itself or proton exchange of zeolite sites. A comparison of crystallinity versus extent of exchange, with crystallinity versus duration of electrochemical procedure (data not shown), shows that the former has a more systematic dependence than the latter. This suggests that the degradation of the structure is due to the protonation of the zeolite and not the electrochemical procedure itself.

The thermal stability of the fresh and exchanged samples was compared by incrementally increasing the temperature of the samples between 298 and $1,173 \mathrm{~K}$ and recording their XRD patterns. Figure 5 shows the thermal stability of the fresh $\mathrm{NaX}$ and electrochemical $\mathrm{HNaX}$ sample. The fresh $\mathrm{NaX}$ sample is stable up to $1,023 \mathrm{~K}$; at this temperature, it is converted to an amorphous phase. The amorphous phase is converted to a crystalline phase at $1,173 \mathrm{~K}$; the diffraction pattern indicates that the crystalline phase is nepheline [20]. The
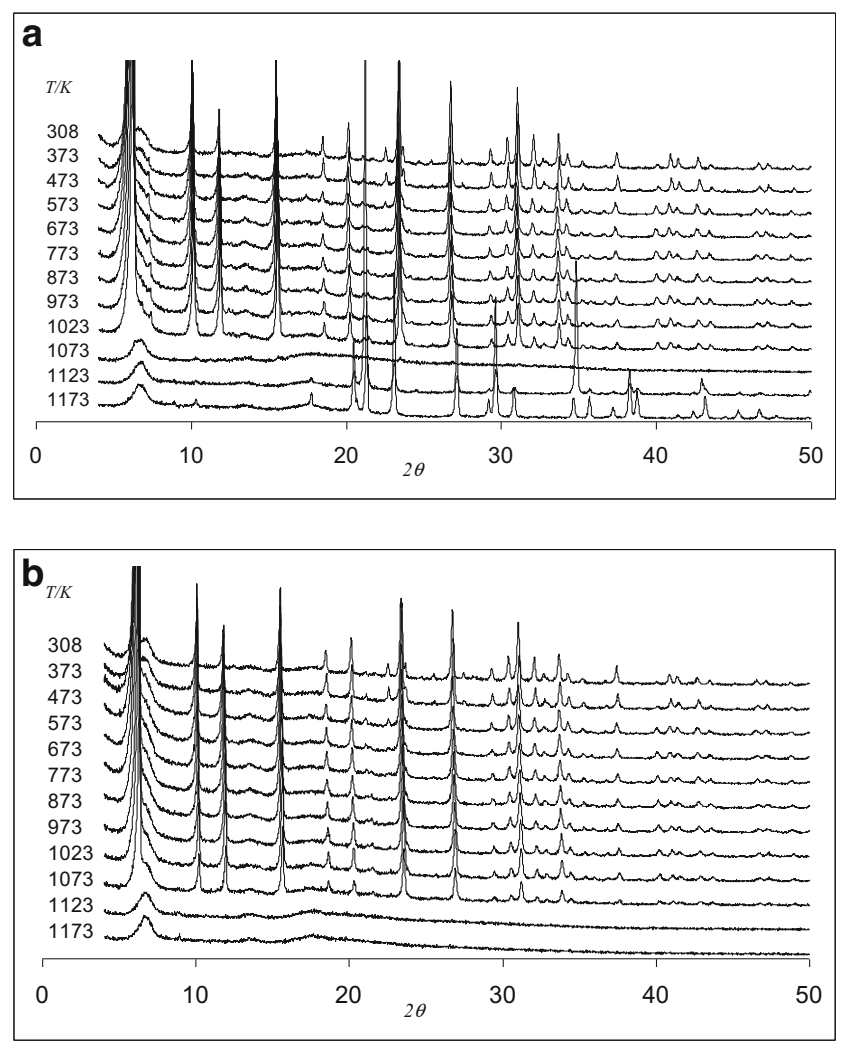

Fig. 5 X-ray powder diffraction patterns at increasing temperature increments of a fresh $\mathrm{NaX}$ sample and b $0.44-\mathrm{HNaX}$ electrochemical sample electrochemical sample retained its original crystallinity up to $1,073 \mathrm{~K}$ and then remains amorphous. Figure 6 shows the thermal stability of the fresh $\mathrm{NaA}$ and electrochemical $\mathrm{HNaA}$ samples. Both samples were stable up to $1,073 \mathrm{~K}$, after which they both convert to an amorphous phase, which is indicated by the lack of diffraction lines and a curved background at $2 \theta \approx 20^{\circ}$. At $1,173 \mathrm{~K}$, the amorphous NaA sample also converts to a crystalline phase; the diffraction pattern indicates that it has converted to nepheline. In contrast, the electrochemical sample remains amorphous up to $1,173 \mathrm{~K}$.

Zeolite thermally induced transformation has been employed as a synthetic route for pure sodium nepheline [20]. $\mathrm{NaA}$ and $\mathrm{NaX}$ have both been employed as the starting material, where nepheline is formed at circa 1,173 K [20]. This is in agreement with the data shown in Figs. 5 and 6. It has been observed that both zeolites go through a carnegiete phases at circa 1,073 K [20]. This framework transformation was not observed for the data shown in Figs. 5 and 6; this is probably due to the different heating regime employed. It should be noted that neither electrochemical samples were converted to nepheline at high temperatures. This is attributed to the reduced sodium content ( $\sim 45 \%$ less than the original zeolite sample) of the electrochemical samples. The product of the thermally induced zeolite transformation products has been shown to be dependent on the counter ion present [21, 22]. Dimitrijević et al. [21] have also shown that $\mathrm{Ca}^{2+}$ -
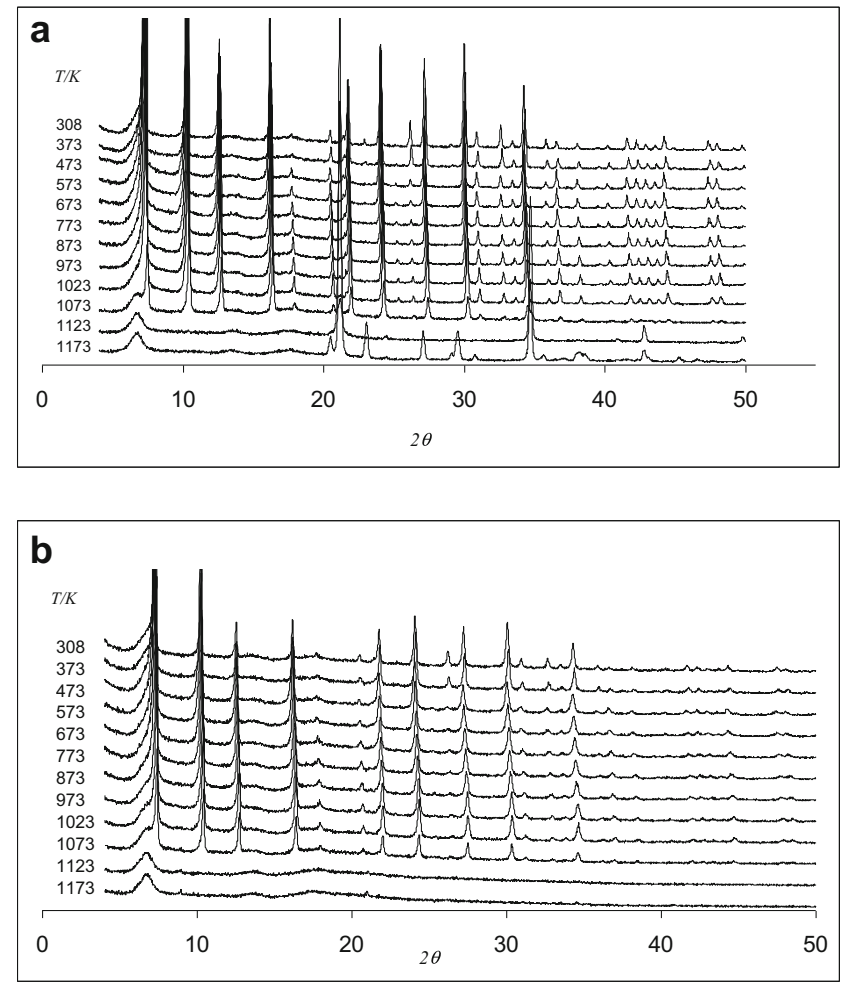

Fig. 6 X-ray powder diffraction patterns at increasing temperature increments of a fresh $\mathrm{NaA}$ sample and b $0.42-\mathrm{HNaA}$ electrochemical sample 
exchanged zeolite $\mathrm{A}$ and $\mathrm{X}$ convert to an anorthite phase at about circa $1,223 \mathrm{~K}$. It is interesting to note that the protonexchanged samples were at least as thermally stable (more stable in the case of the $\mathrm{HNaX}$ sample) as the original zeolite sample. This has important implications for any possible catalytic applications: this is unexpected as protons are believed to weaken the exchange site. It should be noted that we expect the hydrothermal stability of the exchanged samples to be poor $[7,9]$.

Proton magnetic resonance measurements were conducted on some of the samples as a direct measurement of proton exchange. Figure 7 shows the ${ }^{1} \mathrm{H}$-MASNMR spectra of the fresh $\mathrm{NaA}$ and $\mathrm{NaX}$ and corresponding electrochemical samples. The $\mathrm{NaA}$ and electrochemical $\mathrm{NaA}$ samples show a broad feature at $2 \mathrm{ppm}$, which may be due to terminal hydroxyl groups on amorphous aluminium silicate. The peak at $0 \mathrm{ppm}$ is due to silicone-grease impurity introduced when preparing the NMR samples. Importantly, there is no evidence of proton-exchanged sites. The spectra of $\mathrm{NaX}$ and electrochemical $\mathrm{NaX}$ samples show a peak at $1.4 \mathrm{ppm}$ which corresponds to terminal hydroxyl groups. The electrochemical $\mathrm{NaX}$ sample also has a peak at $3.6 \mathrm{ppm}$ which corresponds to exchanged protons, probably in the super cages. These spectra show that significant levels of
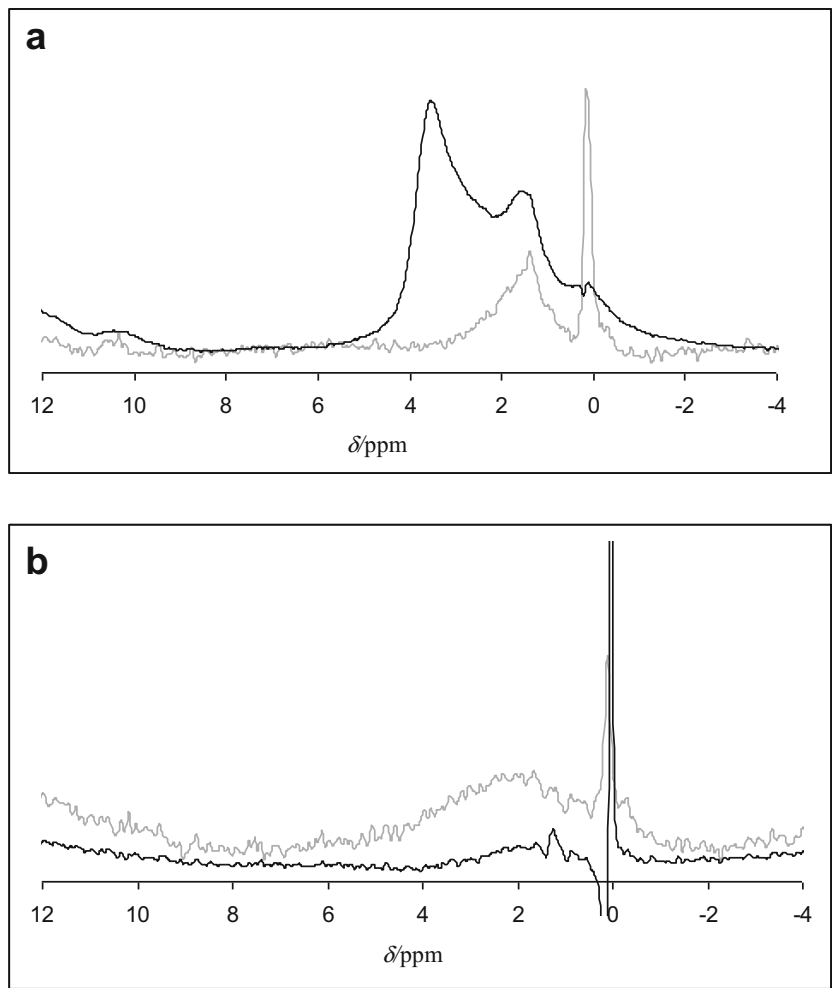

Fig. $7{ }^{1} \mathrm{H}$-MASNMR spectra of a fresh $\mathrm{NaX}$ (grey line) and electrochemical sample $0.36-\mathrm{HNaX}$ (dark line). b Fresh NaA (grey line) and electrochemical sample $0.23-\mathrm{HNaA}$ (dark line) proton exchange have been achieved for $\mathrm{NaX}$; however, this was not observed spectroscopically for NaA.

Dealumination is known to occur when zeolites are subjected to acid treatments $[23,24]$. To investigate this effect, silicon magnetic resonance was conducted on a number of the samples. ${ }^{29} \mathrm{Si}$-MASNMR of zeolites typically gives a fivepeak profile; each peak corresponds to a silicon-atom bound via bridging oxygens to either four, three, two, one or zero aluminium atoms. Figure 8 shows the ${ }^{29} \mathrm{Si}-\mathrm{MASNMR}$ spectra of fresh $\mathrm{NaX}$ and $\mathrm{NaA}$ and corresponding electrochemical samples. The NaX spectrum shows a typical five-peak spectra. The relative peak intensities can be used to calculate the $\mathrm{Si} / \mathrm{Al}$ ratio using Eq. $1[25,26]$.

$$
(S i / A l)_{n m r}=\frac{\sum_{n=0}^{4} I_{S i(n A l)}}{\sum_{n=0}^{4} 0.25 n I_{S i(n A l)}}
$$

Where $I_{\mathrm{Si}(\mathrm{nAl})}$ is the intensity of the NMR peak corresponding to silicon attached to $n$ aluminium atoms. For Fig. 8a, the calculated ratio is approximately 1.49 , which is within the conventional limits for zeolite X. It should be noted that the spectrum was not deconvoluted, and so, the measured ratio is approximate. A comparison of the spectral profile with published experimental and theoretical spectra shows good agreement $[26,27]$. The corresponding electrochemical sample again shows the five-fingered pattern. The peaks are broader, which may be due to an increase in the number resonance lines with slightly different chemical shifts due to different structural environments (i.e. the sample is less crystalline) [25]. The broadening of ${ }^{29} \mathrm{Si}$ lines of less crystalline samples has been previously observed by Lippmaa et al. [28]. The $\mathrm{Si} /$ $\mathrm{Al}$ ratio for the electrochemical sample is calculated as 1.54 (again the spectral profile agrees with published spectra [26, 27] which is equivalent to a $5 \%$ loss in aluminium. The $\mathrm{NaA}$ spectra shows a single peak at $-90 \mathrm{ppm}$, which is expected for zeolites with a $\mathrm{Si} / \mathrm{Al}$ ratio of one (as all silicon atoms have four aluminium neighbours). The corresponding electrochemical sample also shows a peak at $-90 \mathrm{ppm}$, but with a broad feature at $-100 \mathrm{ppm}$. The broad shallow feature is probably due to amorphous regions of the zeolite and can explained by a large number of resonance lines with slightly different chemical shifts due to different structural environments. The peak at $-90 \mathrm{ppm}$ shows no broadening, which suggests that the amorphous and crystalline regions are distinct. It has been observed that the destruction of the zeolite A framework occurs preferentially at the surface of the zeolite particles [11]; this could account for the two distinct phases. A uniform loss in crystallinity would be identified by peak broadening as observed for aluminosilicate gels formed as intermediates in zeolite A synthesis [29]. 

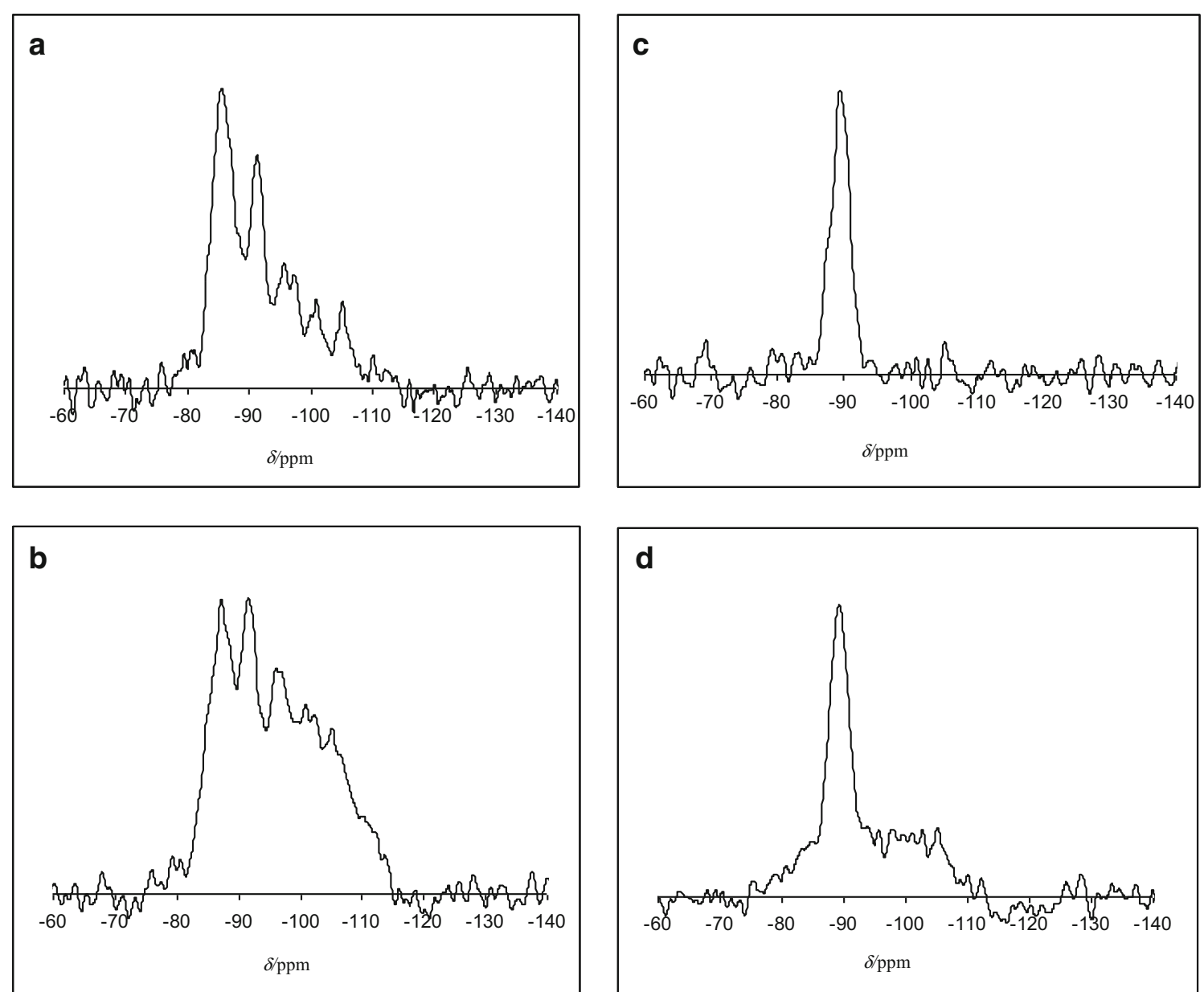

Fig. $8{ }^{29}$ Si-MASNMR spectra of a fresh $\mathrm{NaX}$, b electrochemical sample 0.36-HNaX, $\mathbf{c}$ fresh $\mathrm{NaA}$ and $\mathbf{d}$ electrochemical sample $0.23-\mathrm{HNaA}$

\section{Conclusions}

Complete proton exchange has not been achieved for either $\mathrm{NaX}$ or $\mathrm{NaA}$ by direct proton exchange or via ammonium exchange, whilst retaining good crystallinity (>50\%). In fact, to our knowledge, $>0.5$ exchange has not been achieved whilst retaining good crystallinity (except under anhydrous conditions).

Using the electrochemical method described above, 0.42 proton exchange of $\mathrm{NaA}$ has been achieved with the structure retaining $55 \%$ crystallinity. This compares well with proton exchange employing a flow-through system; using a neutral solution 0.40 proton-exchange achieved was found with complete loss of crystallinity [11]. In each case, it should be noted that the proton exchange could be wholly accounted for by exchange of the non-crystalline regions. Additionally no evidence of proton exchange was observed by ${ }^{1}$ H-MASNMR. ${ }^{29}$ Si-MASNMR data suggest that the crystalline and amorphous phases of the exchange zeolites are distinct.

With $\mathrm{NaX}$, the electrochemical method achieved 0.44 proton exchange with the structure retaining $88 \%$ crystallinity.
${ }^{1}$ H-MASNMR confirm that proton exchange has occurred with this zeolite, and ${ }^{29} \mathrm{Si}$-MASNMR indicates that the electrochemical exchange process occurred with $5 \%$ loss of aluminium. Thermal analysis showed that proton-exchanged material is as thermally stably as the parent zeolite, although it should be noted that the sample is expected to possess lower hydrothermal stability. Overall, it has been demonstrated that electrochemically enhanced ion exchange of zeolites can be carried out successfully under very mild conditions.

Acknowledgments We thank Dr D. C. Apperley, of the EPSRC solidstate NMR service at the University of Durham, for undertaking the ${ }^{1} \mathrm{H}$ and ${ }^{29} \mathrm{Si}$-MASNMR experiments. We thank the EPSRC (Grant reference GR/S11596/01) for financial support.

Open Access This article is distributed under the terms of the Creative Commons Attribution 4.0 International License (http:// creativecommons.org/licenses/by/4.0/), which permits unrestricted use, distribution, and reproduction in any medium, provided you give appropriate credit to the original author(s) and the source, provide a link to the Creative Commons license, and indicate if changes were made. 


\section{References}

1. Ribeiro FR, Alvarez F, Henriques C, Lemos F, Lopes JM, Ribeiro MF (1995) J Mol Catal A Chem 96:245-270

2. Meriaudeau P, Naccache C (1997) Catal Rev 39:5-48

3. Martens JA, Jacobs PA (2001) Stud Surf Sci Catal 137:633-689

4. Csicsery SM (1984) Zeolites 4:202-213

5. Maxwell IE, Stork WHJ (2001) Stud Surf Sci Catal 137:747-795

6. Breck DW (1974) Zeolite molecular sieves. John Wiley \& Sons, London, Chapter 7

7. Kühl GH (1973) J Catal 29:270-277

8. Breck DW, Eversole WG, Milton RM, Reed TB, Thomas TL (1956) J Am Chem Soc 78:5963-5971

9. Kühl GH, Schweizer AE (1975) J Catal 38:469-476

10. Zhu L, Seff K, Olson DH, Cohen BJ, Von Dreele RB (1999) J Phys Chem B 103:10365-10372

11. Cook TE, Cilley WA, Savitsky AC, Wiers BH (1982) Environ Sci Technol 16:344-350

12. Wolf F, Frtig H (1968) Molecular sieves. Soc. Chem Ind, London, p 173

13. Roelofsen DP, Wils ERJ, Van Bekkum H (1972) J Inorg Nucl Chem 34:1437-1448

14. Stephenson MJ, Holmes SM, Dryfe RAW (2005) Angew Chem Int Ed 44:3075-3078

15. Walcarius A (1996) Electroanalysis 8:971-986
16. Fermín DJ, Duong HD, Ding Z, Brevet PF, Girault HH (1999) Phys Chem Chem Phys 1:1461-1467

17. Clarke DJ, Schiffrin DJ, Wiles MC (1989) Electrochim Acta 34: 767-769

18. Freude D, Hunger M, Pfeifer H, Scheler G, Hoffmann J, Schmitz W (1984) Chem Phys Lett 105:427-430

19. Thursfield A, Anderson MW (1996) J Phys Chem 100:6698-6707

20. Dimitrijević R, Dondur V, Vulic P, Markovic S, Macura S (2004) J Phys Chem Solids 65:1623-1633

21. Dimitrijević R, Dondur V, Kremenović A (1996) Zeolites 16:294300

22. Dimitrijević R, Kremenovic A, Dondur V, Tomasevic-Canovic M, Motrovic M (1997) J Phys Chem B 101:3931-3936

23. Kerr GT (1968) J Phys Chem 72:2594-2596

24. Lynch J, Dufresne P (1987) Zeolites 7:333-340

25. Engelhardt G, Michel D (1974) High-resolution solid-state NMR of silicates and zeolites. John Wiley \& Sons, Chichester, Chapter 5

26. Engelhardt G, Lohse U, Lippmaa E, Tarmak M, Mägi M (1981) Z Anorg Allg Chem 482:49-64

27. Klinowski J, Ramdas S, Thomas JM (1982) J Chem Soc Faraday Trans 2(78):1025-1050

28. Lippmaa E, Mägi M, Samoson A, Tarmak M, Engelhardt G (1981) J Am Chem Soc 103:4992-4996

29. Engelhardt G, Fahlke B, Mägi M, Lippmaa E (1983) Zeolites 3: 292-294 